\title{
Association Between Malaria Parasite Density in Pregnancy and Fetal Birth Weight in a University Teaching Hospital
}

\author{
Nwangwa E. K*, Ekhoye E. I. \\ Department ofPhy siology, Faculty of Basic MedicalScience, College of HealthScience, Delta State University, P.M.B 001, Abraka, Delta \\ State, Nigeria
}

\begin{abstract}
Malaria in pregnancy is an obstetric, social and medical problem requiring multidisciplinary and multidimensional solution. In Africa, perinatal mortality due to malaria is at about $1500 /$ day. In areas where malaria is endemic, $20-40 \%$ of all babies born may have complications of malaria.In this Prospective study, two hundred (200) consenting pregnant women who were attending antenatal clinic in a University Teaching hospital who met the inclusion criteria were recruited for the study. Malaria parasitaemia were examined using Giemsa staining of the thick and thin blood films and WBC by coulter automated cell count and QBC centrifugal haematology system. Other parameters (fetal birth weight, gestational age, parity, maternal age) were also documented. The result showed a strongly positive correlation(r $=0.7258)$ and statistically significant $(\mathrm{p}<0.05)$ decrease in birth weight for mild $(3.29 \pm 0.07 \mathrm{~kg}), \operatorname{moderate}(2.86 \pm 1.33 \mathrm{~kg})$ and severe $(2.17 \pm 0.213 \mathrm{~kg})$ paras itamia in primigravida and mild $(3.43 \pm 0.05 \mathrm{~kg})$, moderate $(3.12 \pm 0.05 \mathrm{~kg})$ and severe $(2.92 \pm 0.21 \mathrm{~kg})$ in multigravida.Also found is that the average birth weight in primigravida $(2.85 \pm 0.158 \mathrm{~kg})$ is lower than that of multigravida $(3.07 \pm 0.039 \mathrm{~kg})$. It is therefore, recommended that malaria screening should form part of routine antenatal investigations in malaria endemic regions to prevent the problems associated with low birth weight.
\end{abstract}

Keywords Malaria Parasite Density, Birth Weight, Pregnancy

\section{Introduction}

Malaria causes about 400 - 900 million cases of fever and approximately one to three million deaths annually[1]. The vast majority of cases occur in children under the age of 5 years, pregnant women are also vulnerable[2]. Hundreds of millions are infected each year and it is responsible for one million deaths per year worldwide, $90 \%$ in Africa[3].It is estimated that each year over 30 million women become pregnant in malaria in fected areas of Africa with most living in area of stable ma laria trans mis sion[4]. Despite the effort to reduce transmission and increase treatment, there has been little change in these areas at risk of this disease[5]. Indeed, if the prevalence of malaria stays on its present upwards course, the death rate could double in the next twenty years [1].

Malaria and pregnancy are mutually aggravating conditions. The physiological changes due to malaria have a synergistic effect on the course of each other, thus making the life difficult for the mother, the child and the treating physician. Most epidemiologic studies conducted in the

* Corresponding author:

drezekingx@yahoo.com (Nwangwa, E.K)

Published online at http://journal.sapub.org/phr

Copyright (C) 2012 Scientific \& Academic Publishing. All Rights Reserved malaria endemic countries have found the primigravidae are more susceptible in human malaria than multigravidae[6].

In areas of intense transmission, Plas modium falciparum infection during pregnancy is usually asymptomatic and therefore remains undetected and untreated, despite the presence of parasites in the placenta. The main adverse man ifestations of malaria in pregnancy are maternal anaemia and pre-term delivery [7,8.9].

Malaria parasitaemia has been associated with risk factor for low birth weight babies caused by intra-uterine growth retardation (IUGR) and pre-term deliveries (PTD)[10]. A healthy birth weight is extremely important for newborn as low birth weight babies are more susceptible to health problems, slower development, delayed milestones and low immunity[11]. It is also established as an important risk factor for neonatal morbidity[12]. Therefore, pregnant women must acquire a form of pregnancy-associated immunity during their first pregnancies that helps protect them during subsequent pregnancies[7].

The aim of this study is to find the association between malaria parasite density and birth weight in relation to Primigravida and multigravida.

\section{Materials And Methods}




\subsection{Study Area}

This study was carried out in University of Benin Teaching hospital,Benin City. Edo State Nigeria. It is located at the south- south geographical oil rich region with rain forest Vegetation. Malaria transmission is stable and all-round the year.

\subsection{Study Population, Data Collection, Data Analysis}

The studypopulation was drawn from both primigravid and multigravid women and their newborn babies, and were recruited from March 2009 to October, 2010 as part of prospective study investigating the effect of malaria parasitaemia on fetal birth weight. Women with pregnancy induced hypertension, diabetes mellitus, parity greater than four, renal disease, smokers and other chronic ailments e.g. sickle cell, and asthma were excluded from this study. Maternal age, weight and birth weight of the babies' data were collected for this study.

\subsection{StudyP opulation}

During this course of study, pregnant females with ages ranging from 20 to 44 years attending antenatal clinic at the Obstetrics and Gynecology department of University of Benin Teaching Hospital were considered.All pregnant wo men who presented on different occasions with signs and symptoms of malaria (fever, headache, easy fatigability and weakness) in different trimesters and during labour were tested for malaria. Those who were positive and met inclusion criteria were recruited for the study. The total number of subjects used for the study was 200 pregnant females.

\subsection{Sample Collection and Analysis}

Maternal blood samples were collected during labor by pricking the finger with a sterile lancet and collecting 1 or 2 drops of blood directly on two clean glass slides and immediately thick and thin blood film were made using Giemsa staining technique. The air dried s mears were field stained, flushed in clean water and slanted on a draining rack to air dry. The dried stained smear was microscopically examined at x100 objective (oil immersion). The diagnosis of malaria was based on the identification of asexual plasmodium on the thick blood film while the th in blood film was used to identify species of plasmodium. About $3 \mathrm{ml}$ in tube were transported on ice within 1 hours to a laboratory and within 2 hours of initial sample collection, WBC were counted by a Coulter auto mated cell count (Beckman-Coult er) and a QBC centrifugal haematology system(Becton-Dic kinson Diagnostic system). The density of the parasite attack was determined by counting the number of asexual parasites against 100 leucocytes on the thick blood film and converted to parasite/ $\mu$ las suming the total white blood cell count to be 8000 leucocytes $/ \mu 1$.

Parasite Density $=$ Number of parasites present X 8000

Average WBC count per $\mu$ l of blood $1-10$ parasites/ 100 hpf was regarded as $(+)$ or mild infection 11-100 parasites/ 100hpfwas regarded as (++)or moderate infection 1-10 parasites/1hpf of blood as $(+++)$ or severe infection.

\subsection{Ethical Consider ation}

Institutional approval was obtained from University of Benin Teaching Hospital to conduct the research in the antenatal clinic of Obstetrics and Gynaecology department.

\subsection{Statis tical Analysis}

Statistical analysis of measures of central tendency and dispersion of variables (gestational age, maternal age, parity and fetal birth weight) was performed. Evaluation of the relationship between parasite density and fetal birth weight was analysed by Pearson;s correlation coefficient and statistical significance by students $t$-test. All analysis was performed using SPSS version 17.0. The level of signifi cance was considered at $\mathrm{P}<0.05$.

\section{Results}

More number of women in this study group were in the young and prime reproductive period age category. i.e. $<25$ years of age (36\%) followed by 25 - 30 years $(33 \%)$ and $>30$ years $(31 \%)$.

Table 1. Demographic and Reproductive Characteristics of Pregnant Women Infected with Malaria $(\mathrm{n}=200)$, Benin, Nigeria, 2009-2010

\begin{tabular}{ccc}
\hline Characteristics & \multicolumn{2}{c}{ Subjects } \\
\cline { 2 - 3 } Age group & 72 & $\%$ \\
$<25$ years & 66 & 36 \\
$25-30$ years & 62 & 33 \\
$>30$ years & & 31 \\
Gestat ional age & 60 & 30 \\
$<37$ weeks & 112 & 56 \\
$\quad 37-40$ weeks & 28 & 14 \\
$>40$ weeks & 112 & 56 \\
Gravida (Birth weight $(\mathrm{kg})$ & 88 & 44 \\
Primigravidae $(2.85 \pm 0.158)$ &
\end{tabular}

Among the subjects, $56 \%$ had a term delivery with gestational age at delivery (37-40) weeks, $30 \%$ of the subjects having a preterm delivery (Table I).

The primigravid women (56\%) had the parasitaemia and the mean birth weight of babies $(2.85 \pm 0.158) \mathrm{kg}$ while the multigravida wo men (44\%) had babies of mean weight $(3.07$ $\pm 0.039) \mathrm{kg}$. This shows that as parity increases, the intensity of the infection decreases and the incidence of low birth weight also decrease $(\mathrm{p}<0.05)$.

As shown in the table below (Table II), $48 \%$ of the wo men had mild $(+)$ malaria parasitaemia infection with the mean birth weight $(3.29 \pm 0.065), 32 \%$ had moderate $(++)$ infection with the mean birth weight $(2.86 \pm 0.133) \mathrm{kg}$ and $20 \%$ of the women had a severe $(+++)$ infection with the mean birth weight of their babies $(2.17 \pm 0.213) \mathrm{kg}$ which is a low birth weight compared to the normal birth weight $(\geq$ $2.5 \mathrm{~kg}$ ). There was a significant decline in fetal birth weight as the density of parasitaemia increased. The babies born by 
mothers with severe $(+++)$ parasitaemia infection were seriously affected as they had very low birth weight $(<$ $2.50 \mathrm{~kg}$ ) as against normal birth weight.

Table 2. Association bet ween Malaria parasite density and birth weight

\begin{tabular}{|c|c|c|c|c|c|}
\hline $\begin{array}{c}\text { Fe talbi } \\
\text { rth } \\
\text { weight } \\
\text { (kg) }\end{array}$ & $\begin{array}{c}\text { Nu } \\
\mathbf{m b} \\
\text { er }\end{array}$ & $\begin{array}{c}\text { Perce } \\
\text { ntage } \\
\text { s }\end{array}$ & Mild (+) & $\begin{array}{c}\text { Mode rate } \\
(++)\end{array}$ & $\begin{array}{c}\text { Se vere } \\
(+++)\end{array}$ \\
\hline $\begin{array}{c}\text { Primig } \\
\text { ravida }\end{array}$ & $\begin{array}{c}11 \\
2\end{array}$ & 56 & $\begin{array}{c}3.29 \pm 0.07 \\
(48 \%)\end{array}$ & $\begin{array}{c}2.86 \pm 0.13( \\
32 \%)^{*}\end{array}$ & $\begin{array}{c}2.17 \pm 0.21 \\
(20 \%)^{* *}\end{array}$ \\
\hline $\begin{array}{c}\text { Mul tig } \\
\text { ravida }\end{array}$ & 88 & 44 & $\begin{array}{c}3.43 \pm \\
0.05(58 \%)\end{array}$ & $\begin{array}{c}3.12 \pm 0.67( \\
30 \%)^{*}\end{array}$ & $\begin{array}{c}2.92 \pm 0.21 \\
(12 \%)^{* *}\end{array}$ \\
\hline
\end{tabular}

$* \mathrm{P}<0.05$ compared with the Mild Parasitaemia, ** $\mathrm{p}<0.05$ compared with the Moderate parasitaemia. $\mathrm{r}=0.7258$.

\section{Discussions}

Pregnancy and the physiological changes associated with it has been shown to be a predisposing factor to malaria, its associated maternal anaemiaand the resultant reduction in birth weight. Atypical man ifestation of malaria is common in pregnancy, particularly in the second half of pregnancy.

Malaria during pregnancy has been reported to be an important determinant of fetaloutcome[13, 8]. Findings from this study indicates that malaria parasitaemia significa ntly $(\mathrm{P}<0.05)$ decreases fetal birth weight; this reduction in fetal birth weight is highly dependent on the degree of parasitaemia. With increasing number of pregnan cies, the incidence of low birth weight is reduced[14], with primigravida having an average birth weight of $2.85 \pm$ $0.158 \mathrm{kgand}$ multig ravida $3.07 \pm 0.039 \mathrm{~kg}$. The increased risk of ma laria among primigravidae has been well described[7], and is again seen in this study population. According to Brabin,[13] the reduction in birth weight is usually more marked in primigravidae but can extend to second and third gravidae in areas of low malaria transmission [15].

Also in this study most of the subject $(56 \%)$ had term delivery (37-40 weeks) showing that malaria does not have any significant effect on the gestational age at delivery this was similar to other findings where the two main Plas modium species, P. falciparum and P. vivax, were associated with lowbirth weight, but they do not reduce gestational age $[15,16,17,18]$.

\section{Conclusions}

It is obvious from this study that malaria parasitaemia in pregnancy has a negative effect on fetal birth weight. Therefore, there is an urgent need for an intensified effort against malaria in pregnancy by the adoption, practice and the sustainability of the measures targeted at preventing malaria transmission in order to guide against the risk of maternalanaemia in pregnant wo men and also to reduce fetal morbidity, still birth, and in fant mortality that results from low birth weight attributable to malaria during pregnancy. The use of intermittent prophylactic therapy (IPT) in pregnancyis therefore highly encouraged especially in malaria endemic area.

\section{Recommendations}

It is recommended therefore, that malaria control practices should form part of safe motherhood and should be sponsored from the national health scheme fund and made available and accessible at all levels of health care system.

\section{ACKNOWLEDGEMENTS}

The researchers wish to thank the staff of Obstetrics and Gynaecology department of University of Benin Teaching Hospital for their support and ass istance

\section{REFERENCES}

[1] Breman J (2001); The ears of the hippopotamus; Manifestation, determinants and estimates of malaria burden; AMJ Trop Med publisher, New-Jersey

[2] Greenwood B M, Greenwood AM, Bradley AK, Byass P, Jammeh K, Marsh K et al. 1987M ortality and morbidity from malaria among children in a rural area of the Gambia, West Africa. Transactions of the Royal Soceity of Tropical Medicine Hy geine; 81 : 478-486

[3] WHO (2010). Roll Back Malaria WHO partnership. "Economic costs of malaria"

[4] World Health Organization/UNICEF. 2003. Africa malaria report 2003. WHO/CDS/MAL/2003.1093. World Health Organization, Geneva, Switzerland.

[5] Hay S, Guerra C, Tatem A, Noor A, Snow R (2004). "The global distribution and population at risk of malaria: past, present, and future". Lancet Infect Dis 4 (6): 327-36.PMID 15172341 .

[6] Bray R.S, Anderson M.J., (1979) Falciparum Malaria and Pregnancy. Transactions of the Royal Soceity of Tropical Medicine and Hy giene; 73:427-431

[7] Brabin BJ (1983) An analysis of malaria in pregnancy in Africa. Bulletin of the World Health Organization 61, $1005-1016$

[8] Menendez C (1995) Malaria during pregnancy: a priority area of malaria research and control. Parasitology Today 11,178 183.

[9] Steketee RW, Nahlen BL, Parise ME \& Menendez C (2001) The burden of malaria in pregnancy in malaria-endemic areas. American Journal of Tropical Medicine and Hygiene 64, $28-35$.

[10] McGregor I.A.,Wilson M.E., Billewicz W.Z. (1983). 'Malaria infection of the placental in the Gambia West Africa. Its incidence and relationship to still birth, birth weight and placental weight'.transections of the Royal Soceity of Tropical Medicine and Hygeine; 77:232-244. 
[11] Walter PR, Garin Y, Blot P.1982 Placental pathologic changes in malaria. A histological and Ultrastructural study. American Journal of Pathology; 109: 330-342.

[12] Borja JB, Adair LS 2003 Assessing the net effect of young maternal age on birth weight, American Journal of Human Biology 15 (6) 733-740

[13] Brabin BJ. (1991): The risks and severity of malaria in pregnant women. In: Applied field in malaria reports, no. 1. Geneva, Switzerland: World Health Organization,.(TDR/FIE LDMAL/ 1).

[14] Brabin, B. and Piper, C. (1997). Anaemia and malaria attributable low birth weight in two population in Papua New Guinea. Ann. Human Biol. 24: 547-555
[15] NostenF,Kuile FO, Maelankirri L, (1991). Malaria during pregnancy in an area of unstable endemicity. Trans R Soc Trop Med Hy g;85:424-9.

[16] Nosten F, McGready R, Simpson JA, (1999). The effects of Plasmodium vivax malaria in pregnancy. Lancet;354: 546-9.

[17] Dolan G, Kuile FO, Jacoutot V, (1993). Bed nets for the prevention of malaria and anaemia in pregnancy. Trans $\mathrm{R}$ Soc Trop Med Hyg;87:620-6.

[18] Nosten F, terKuile F, Maelankiri L, (1994). Mefloquine prophylaxis prevents malaria during pregnancy: a double-blind, placebo-controlled study. J Infect Dis 169:595-603. 